\title{
An Intelligent Knowledge-based Approach for the Management of Human Immunodeficiency Virus and Tuberculosis
}

\author{
Djam Xaveria Youh \\ Department of Computer Science, \\ University of Yaounde I, \\ P.0. Box 812, Yaounde, Cameroon
}

\begin{abstract}
Dealing with Human Immunodeficiency Virus (HIV) and Tuberculosis (TB) as co-infection is not easy. Stigmatization, rejection and discrimination of TB and HIV patients have become the major challenges in medical field which makes it very difficult for the health care professionals to communicate with their patients. The inherent complexities of medical practices make traditional approaches of diagnosis and predicting treatment outcome inappropriate. There is the need for the provision of a system to mitigate these effects.
\end{abstract}

Till date, the research done on Fuzzy Cognitive Maps have not been able to effectively handle missing data in order to predict the patient health status in spite of many existing methods of dealing with missing data. In this paper, a new diagnostics predictive algorithm of fuzzy cognitive map was developed to improve the efficiency of the prediction of patient health status in case of HIV or TB. The system is an advancement of that proposed by Djam and Kimbi in 2011, with an additional factors on effective prediction measures. The diagnosis and treatment processes were modeled based on Domain Experts' judgments. The approach proposed in this paper was validated using real patient data and the experimental results of the research show that the new proposed algorithm can effectively simulate the behavior of a medical expert and was successfully employed in designing computer-based diagnostic predictive models for effective patient management.

\section{Keywords}

Medical Diagnosis, Treatment Outcome, Computational Intelligence, Logistic Regression, Fuzzy Cognitive Map, Diagnostic Predictive Model, Fuzzy Diagnostics Algorithm.

\section{INTRODUCTION}

The ability of the Health Care Sector to effectively handle stigmatization, rejection and discrimination of tuberculosis (TB) and Human Immunodeficiency Virus (HIV) patients in this present era will no doubt depend largely on the development of their Information Technology (IT) infrastructure. HIV and TB are characterized by the process of opportunities infections [1]. Since both diseases are endemic and the length of infection for both diseases can be several years, the burden of co-infection is a real and pressing problem. In the bid to handle these challenges while managing medical uncertainty, an intelligent system needs to be adopted in order to improve the quality of health care delivery. The challenges of rapid technological changes and growing patients' expectation reinforced the need for a vibrant Medical Expert System for quality patient management. As a result of this, there is a greater need for a system that will not only simplify the diagnosis of tuberculosis but equally provide an automatic procedure for effective patient monitoring and predicting destination after treatment. This is due to the fact that today's medical world is one with increasing access to intelligent systems and exploring research regarding patient destination after treatment is of paramount importance as this will help to reduce mortality rate [2].

In recent times, Artificial Intelligent (AI) methods have significantly been used in medical applications as complementary solutions to traditional approaches of analysis, however, no explicit attempts are made to integrate Fuzzy Cognitive Maps and Logistics Regression to address pattern discovery for proper effective medical decision. Fuzzy Cognitive Maps (FCMs) provide a unique way to arrive at a definite conclusion from vague, imprecise and ambiguous medical data.

The emergence of information technology (IT) has opened unprecedented opportunities in health care delivery system as the demand for intelligent and knowledge-based systems has increased as modern medical practices become more knowledge-intensive [2]. Physician intuitively exercise knowledge obtained from previous patients' symptoms. In everyday practice, the amount of medical knowledge grows steadily, such that it may become difficult for physicians to keep up with all the essential information gained. To quickly and accurately diagnose a patient, there is a critical need in employing computerized technologies to assist in diagnosis and access the related information. Computer-assisted technology is certainly helpful for inexperienced physicians in making medical diagnosis as well as for experienced physicians in supporting complex decisions. The complexity of medical practices makes traditional approaches of diagnosis inappropriate [2]. Computer-assisted technology has become an attractive tool to help physicians in retrieving medical information as well as in making decision faced in today's medical complications. Most medical diagnosis is full of imprecision and uncertainty. FCM which is one of the soft computing techniques can render precise what is imprecise inherent in medical diagnosis. Fuzzy logic is rapidly becoming a successful technique for developing sophisticated applications because it can suitably address complex problems [13-15]. It resembles human decision making with an ability to generate precise solutions from certain or approximate information. While other soft computing techniques require accurate information to model real-world behaviors, fuzzy design can accommodate real-world ambiguities. It provides both an intuitive method for describing a system in human terms and automates the conversion of those system specifications into effective models. FCMs can be used effectively for medical diagnosis, Prediction and monitoring because of its ability to generate precise output from imprecise and ambiguous data inherent in medical diagnosis. 
The adages "A healthy nation is a wealthy nation" and "Prevention is better than cure" are still valid today because it is only with good health a man can make wealth. However, in a case where a person is already sick, diagnosis, treatment and effective monitoring are inevitable to avoid untimely death and quality patient management can only be feasible when there is a vibrant Medical Expert System. HIV and TB represents major public health problems in the whole world especially in the tropics [4]. The need to arrive at the most accurate medical diagnosis in a timely manner and adequate treatment management is heightened in the case of HIV and TB. In fact, ensuring that HIV AND TB patients completes therapy to cure in order to prevent drug resistance cases and developing TB in the community is one of the crucial objectives of DOTS (directly-observed treatment, short course)[1]. At the same time, World Health Organization [9] has highlighted the necessity of improving the quality of diagnosis and treatment in terms of patients-support and health workers-supervision in reducing the rate of mortality. However, there is no way to measure how intensive patientssupport and health workers-supervision should be for the patients. In order to make this supervision more contextspecific and patients-sensitive, a tool to diagnose the level of severity of the disease, monitors and equally predict patients' destination regarding treatment outcome is necessitated. There is, therefore, a dual need for a better tool to predict patient chances of survival after treatment.

Owing to the complexity occurring in the management of HIV and $\mathrm{TB}$, there are continuous challenges of building more advanced methodologies that are in rapport with the reality. In recognition of the need to have a methodical means to improve on the available diagnostic and treatment modalities for HIV and TB in order to reduce the rate of mortality, an evidence-based diagnostic predictive model is desired. This paper seeks to present a novel diagnostic predictive algorithm for the management of HIV AND TB based on the integration of FCM and Logistics Regression. The developed medical expert system can provide an intelligent decision support platform to healthcare providers by assisting them to recognize how intensive their care should be for each specific patient based on the prediction results. Computer based techniques have been extensively examined for improving diagnosis and treatment of diseases and until today remains an active research area [6-11].

\section{RELATED WORK}

The concept of a fuzzy set was originally proposed by [10] as an extension of the notion of a set by allowing partial membership, and the usage of fuzzy sets theory in medical applications can be traced back early to work by [11, 12] who advocated and put the foundations of the theory to model relationships of symptoms and diseases by using the compositional rule of inference (CRI) as an inference mechanism. Fuzzy Cognitive Maps FCMs, which were introduced by [5] as an extension of Cognitive Maps, are powerful tools for modeling dynamic systems. A Fuzzy Cognitive Map (FCM), as a branch of fuzzy logic, is a causal knowledge-driven methodology for modeling complex decision systems originally developed by [5].

The department of computer science, University of Botswana developed an online expert system to provide the general public with information related to HIV and AIDS [16]. The system would be queried by users using mobile phones technology. The system accepts frequently asked questions (FAQ) as inputs from the users and provides the appropriate answer to the question posed. It consists of user interface, inference engine and knowledge base. The user interacts with interface which consists of graphical screen. A question is typed on the screen and a response is displayed from the system. The inference engine uses the problem-solving logic to emulate the decision-making of a domain expert. The knowledge base is built from mainly the FAQS and answers manual of a local HIV/AIDS information call center [16]. The system was found to be a good system to disseminate HIV/AIDS information. More than 90 percent of the participant found it easy to use the system. They found the system useful in their own HIV/AIDS health care support. However the knowledge base showed some uncertainties. There was a possibility that the knowledge base could not provide the expected response to the users in some cases and could not effectively predict patient health status.

Few frameworks based on fuzzy cognitive maps for medical reasoning have been proposed [3, 6, 7 and 8]. Due to the fact that, the complexities of medical practice makes traditional approaches of analysis inappropriate, this multi-expert approach presented by these researchers would had efficiently aid in medical decision but for the fact that they did not base on accuracy and interpretability. "Improving accuracy while maintaining interpretability" is the main focus of a Clinician. In view of the above, the performance of a FCM model can extensively increase by using classified fuzzy decision tree.

HIV and TB are co-infection in which treatment procedure is known to be long. A number of methods have been elicited to study the management of these deseases. In a recent research, a fuzzy expert system for tuberculosis diagnosis was developed [2]. The main focus of the work was accuracy and no doubt, the researchers would have achieved "high peak" accuracy. But a physician involved in sensitive decision making about a patient's treatment, demands more than that. Factors including interpretability, system's ability to adopt human reasoning to deal with uncertainties and performance consistency were ignored. In this work, FCM is investigated to diagnose HIV and TB to show its functionality. The results were compared with those in [2] and showed that the diagnostic process can further be improved using FCM. According to our approach, the performance of the FCM model was improved by using Fuzzy Decision Tree to generate meaningful IF-THEN rules and integrating the FCM model with logistic regression produced a novel diagnostic predictive model for effective patient management.

The review of related literature shows that there is a painful lack of diagnostic predictive models for HIV AND TB management and no explicit attempts are made to utilize Fuzzy Cognitive Maps to address pattern discovery for proper medical decision.

\section{MATERIALS AND METHODS 3.1 Data}

For data gathering, patients' medical records on HIV and TB were sourced from Central Hospital, Yaounde, Cameroon from 2008 to 2014. Personal interview was conducted with three Medical Domain Experts (Physicians) in order to get the necessary data for this study. A total of 200 patients' medical records were sampled. The method of sampling strategy adopted was systematic sampling method. In this sequel, an honest attempt to incorporate fuzzy cognitive map as a knowledge-based modeling technique in conjunction with logistic regression to produce a novel diagnostic predictive model for the management of HIV and TB. 


\subsection{Developed Fuzzy Diagnostic Predictive Algorithm}

In order to succeed to the goal of improving the diagnostics predictive efficiency of FCMs, a new diagnostics predictive algorithm for FCM is proposed. The proposed algorithm for the diagnostic predictive process of diseases is presented below:

Let $\boldsymbol{D}$ denotes the number of diseases, $D=\left(d_{1}, d_{2}, d_{3}, d_{4}\right)$, whereby $d_{i} \in D$, represents the set of all possible diseases.

Let:

\section{$M_{\text {InitialWeight }}$ \\ $M_{\text {OverallWeight }}$ \\ $\mathrm{D}_{\text {set }}$ \\ $\mathrm{D}_{\text {Test }}$ \\ $\mathrm{D}_{\text {Training }}$}

Step 1:

Step 2:

Step 3:

$$
M_{\text {OverallWeight }}=f\left(\sum_{i=1}^{n}\left(M_{\text {InitiialWeight }}\right)_{i}\right)
$$

Step 4:

Construction of an augmented FCM.

Step 5:

Step 6:

\subsection{Fuzzy Cognitive Map-based Decision Support Tool}

Three Physicians - Medical Domain Experts from Central Hospital, Yaounde, Cameroon were pooled together to define the number of parameters (Concepts) concern with HIV and
TB management. These concepts are listed in Table 1 and Table 2 with their associated linguistics variables. For this application, 9 concepts with 9 fuzzy sets for HIV and 13 Concepts with 13 fuzzy sets for TB respectively were suggested by three medical domain experts. The Decision Concepts (DS $\left.{ }^{1}\right)$ and $\left(\mathrm{DS}^{2}\right)$ represents the severity of HIV and TB infection respectively. $\mathrm{DS}^{1}$ was categorized as Type 1 and Type 2 while $\mathrm{DS}^{2}$ takes four fuzzy values (Mild, Moderate, Severe, Very Severe) as shown in Table 1 and Table 2. The identified concepts with their associative fuzzy sets keep relation with each other, in other to characterize the process of diagnosing HIV and TB. After the determination of fuzzy sets, each expert was asked to define the degree of influence among the concepts and equally describe their interrelationships using IF-THEN rules derived from fuzzy decision tree and the inferred fuzzy weights were combined and normalized using sigmoid function and the result was a crisp value representing the weight of each interconnection. In this way, the weights of interconnections between the concepts were determined and the FCM tools for HIV and TB were constructed based on expert judgment and intuition.

Table 1: Fuzzy Sets for Human Immunodeficiency Virus

\begin{tabular}{|c|c|}
\hline Concepts & Linguistic Variables \\
\hline $\mathrm{C} 1$ : Cough>one Month & $\begin{array}{l}\text { None (No Cough), Moderate } \\
\text { (Productive Cough), Severe(Non- } \\
\text { Productive Cough) }\end{array}$ \\
\hline C2: Fever & $\begin{array}{l}\text { None, Mild(Low grade fever: } 36^{0} \text { - } \\
38.4^{0} \text { ), Severe (high grade fever } \\
>38.5^{0} \text { ) }\end{array}$ \\
\hline C3: Weight Loss & $\begin{array}{l}\text { None, Mild, Moderate, Severe and } \\
\text { Very Severe }\end{array}$ \\
\hline C4: Diarrhoea & $\begin{array}{l}\text { Absence, Presence } \quad(\text { Absence }=0, \\
\text { Presence }=1)\end{array}$ \\
\hline C5: Waisting & $\begin{array}{l}\text { Absence, Presence } \quad \text { Absence }=0, \\
\text { Presence }=1)\end{array}$ \\
\hline C6: Lymphadenopathy & $\begin{array}{l}\text { Absence, Presence }(\text { Absence }=0, \\
\text { Presence }=1)\end{array}$ \\
\hline C7: Karposi Sarcoma & $\begin{array}{l}\text { Absence, Presence }(\text { Absence }=0, \\
\text { Presence }=1)\end{array}$ \\
\hline $\begin{array}{l}\text { C8: Toxoplasmosis of } \\
\text { the Brain }\end{array}$ & $\begin{array}{l}\text { Absence, Presence } \quad \text { (Absence }=0 \text {, } \\
\text { Presence }=1)\end{array}$ \\
\hline $\begin{array}{l}\mathrm{DS}^{1} \text { : Severity of the } \\
\text { Disease }\end{array}$ & Type 1 , Type 2 \\
\hline
\end{tabular}

Table 2: Fuzzy Sets for Tuberculosis

\begin{tabular}{|l|l|}
\hline Concepts & Linguistic Variables \\
\hline C1: Cough>3 weeks & $\begin{array}{l}\text { None (No Cough), Moderate } \\
\text { (Productive Cough), Severe(Non- } \\
\text { Productive Cough) }\end{array}$ \\
\hline C2: Headache & $\begin{array}{l}\text { None, Mild, Moderate, Severe and } \\
\text { Very Severe }\end{array}$ \\
\hline
\end{tabular}




\begin{tabular}{|c|c|}
\hline C3: Constipation & $\begin{array}{l}\text { Absence, Presence } \quad(\text { Absence }=0, \\
\text { Presence }=1)\end{array}$ \\
\hline C4: Fever & $\begin{array}{l}\text { None, Mild(Low grade fever: } 36^{0}- \\
38.4^{0} \text { ), Severe (high grade fever } \\
>38.5^{0} \text { ) }\end{array}$ \\
\hline $\begin{array}{l}\text { C6:Drenching night } \\
\text { sweats }\end{array}$ & $\begin{array}{l}\text { Absence, Presence } \quad(\text { Absence }=0, \\
\text { Presence }=1)\end{array}$ \\
\hline C5: Weight Loss & $\begin{array}{l}\text { None, Mild, Moderate, Severe and } \\
\text { Very Severe }\end{array}$ \\
\hline C7: Loss of appetite & $\begin{array}{l}\text { Absence, Presence } \quad(\text { Absence }=0, \\
\text { Presence }=1)\end{array}$ \\
\hline C8: Anaemia & $\begin{array}{l}\text { None, Mild, Moderate, Severe and } \\
\text { Very Severe }\end{array}$ \\
\hline C9: Sputum AFB & $\begin{array}{l}\text { None, } \quad(+) \text { Mild, } \quad(++) \text { Moderate, } \\
(+++) \text { Severe, }(++++) \text { Very Severe, }\end{array}$ \\
\hline C10: Mantoux Test & $\begin{array}{l}\text { None }(0-5 \mathrm{~mm}), \text { Mild }(5-6 \mathrm{~mm}) \text {, } \\
\text { Moderate }(7-8 \mathrm{~mm}) \text {, Severe }(9-10 \mathrm{~mm}) \\
\text { and Very Severe }(>=10 \mathrm{~mm})\end{array}$ \\
\hline $\begin{array}{l}\text { C11: Haemoptysis } \\
\text { (Coughing of blood) }\end{array}$ & $\begin{array}{l}\text { Absence, Presence } \quad(\text { Absence }=0, \\
\text { Presence }=1)\end{array}$ \\
\hline $\begin{array}{l}\text { C12:Tachypnea } \\
\text { (Fast Breathing) }\end{array}$ & $\begin{array}{l}\text { Mild, Moderate, Severe and Very } \\
\text { Severe }\end{array}$ \\
\hline $\begin{array}{l}\mathrm{DS}^{2} \text { : Severity of the } \\
\text { Disease }\end{array}$ & $\begin{array}{l}\text { Mild, Moderate, Severe and Very } \\
\text { Severe }\end{array}$ \\
\hline
\end{tabular}

According to domain experts' judgments, input variables selected for this research were described with the following linguistic variables (None, Mild, Moderate, Severe, Very Severe, Presence, Absence) in the fuzzy interval of $[0,1]$. On the basis of the Experts, the relationships between concepts were described with eight linguistic variables (Negatively Strong, Negatively Moderate, Negatively Weak, Negatively Very Weak, No Relationship, Positively Weak, Positively Moderate, Positively Strong, and Positively Very Strong) in the fuzzy interval of $[-1,1]$ as shown in table 4 . In view of this, the fuzzy ranking for our developed system is shown in tables 3 and 4 respectively (These fuzzy values were categorized and classified based on Experts' Judgments).

Several formulas can be used as the threshold activation /tranformation function in a FCM system. The threshold function is used to reduce unbounded weight sum to a certain

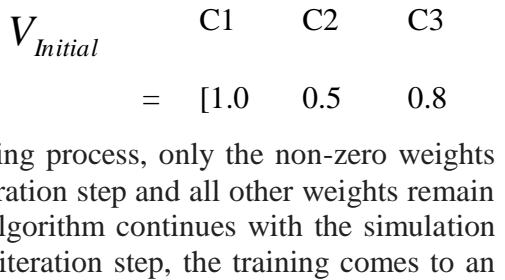

range. For this application, the logistic Signal Function was used as the threshold function. The logistic Signal Function (Sigmoid Function) $f$, is a threshold function used in this research for two reasons:

i.) To normalize linguistic weights in the interval $[-1,1]$

ii.) To normalize concepts' values in the interval $[0,1]$

It is a continuous function and provides true fuzzy conceptual node states. The function is:

The constant, c, is critical in determining the degree of fuzzification of the function, $\mathrm{c}=1$ was chosen as a trade-off which favors the fuzzy interval $[0,1]$ and the variable $x$ denotes concepts.

\section{EXPERIMENTAL RESULTS AND DISCUSSION}

The lack of evidence-based diagnostic predictive models for TB limits effective patient management. A number of HIV and TB cases were diagnosed using the proposed novel diagnostics predictive algorithm of FMCs. The FCM performance was illustrated by means of simulating various scenarios of HIV and TB infection. In spite of many existing methods of dealing with missing data [17], in the case of FCMs, there were no previous research attempts to deal with this issue effectively in order to predict the patient health status for timely medical intervention. For the purposes of this paper, FCMs in conjunction with Binary Logistics Regression method was implemented in SPSS Software. Each of the scenario was implemented with initial concepts values from Medical Domain Experts and values from the augmented FCM and the corresponding overall weight matrix as in Figure 1, Figure 2, Table 4 and Table in Appendix.

\subsection{Experimental Results stimulated for Human Immunodeficiency Virus and Tuberculosis}

Human Immunodeficiency Virus Scenario: For this scenario, a young patient health status (with respect to HIV) with patient identification number as 025 was considered, with Cough > One Month $(\mathrm{C} 1=1.0)$, Moderate Fever $(\mathrm{C} 2=0.5)$, Severe Weight Loss $(\mathrm{C} 3=0.8)$, Diarrhea $(\mathrm{C} 4=1.0)$, Waisting (C5=1.0), Lymphadenopathy $(\mathrm{C} 5=1.0)$, Karposi Sarcoma $(C 7=1.0)$, Toxoplasmosis of the Brain $(C 8=1.0)$,

Thus the initial state vector (Input Vector) $V_{\text {Initial }}$ is:

$\begin{array}{lllll}\text { C5 } & \text { C6 } & \text { C7 } & \text { C8 } & \text { DS }^{1} \\ 1.0 & 1.0 & 1.0 & 1.0 & 0]\end{array}$

end and the updated concept values which indicates that the equilibrium region is reached at a fixed point with the final state vector (Decision Output Vector) $V_{\text {Final }}$ as:

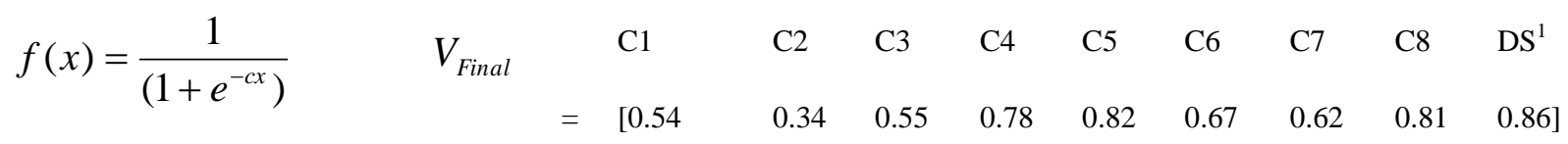


The calculated value of the decision concept $\left(\mathrm{DS}^{1}=0.86\right)$ indicates that patient number 025 was diagnosed with Type 1 and Type 2 HIV with $86 \%$ possibility with gives the result specified by the domain experts.

Tuberculosis Scenario: For this scenario, an immunocompromised patient health status (with respect to tuberculosis) with patient identification number as 015 was

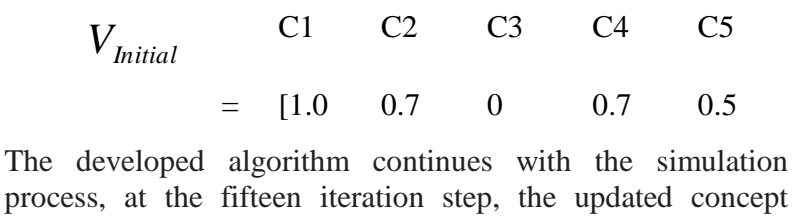

\begin{tabular}{|c|c|c|c|c|c|c|}
\hline$V_{\text {Final }}$ & $\mathrm{C} 1$ & $\mathrm{C} 2$ & C3 & $\mathrm{C} 4$ & C5 & C6 \\
\hline & {$[0.89$} & 0.78 & 0 & 0.69 & 0.75 & 0.87 \\
\hline
\end{tabular}
values which indicates that the equilibrium region is reached

The calculated value of the decision concept $(\mathrm{DS}=0.82)$ indicates that patient number 015 was diagnosed for very severe TB with $82 \%$ possibility with gives the result specified by the domain experts.

Similarly, the results for the other patients were computed and got results that were in the range of predefined limits by the Medical Domain Experts as shown in Table xxx.

This model can determine the level of patient support and supervision as seen in the cases of patient ID 025 with Type 1 and Type 2 HIV and patient ID 015 with very severe TB, by assisting the healthcare providers to recognize how intensive their care should be for each specific patient in order to reduce the rate of mortality.

\subsection{Performance Evaluation of Fuzzy \\ Diagnostic algorithm}

The performance of the algorithm was tested using Mean Absolute Error (MAE). The objective of this metric is to ascertain if there exist any major difference between the actual and the desired output concepts of the developed fuzzy diagnostic predictive algorithm. The MAE performance index is defined as follows:

$M A E=\frac{1}{M}\left(\sum_{k=1}^{M} \sum_{l=1}^{N}\left|D O C_{l k}^{\text {Real }}-D O C_{l k}^{\text {Predticted }}\right|\right)$

Where $\mathrm{M}$ is the number of training sets $(\mathrm{M}=14), \mathrm{N}$ is the number of System Output Concepts $\left(\mathrm{N}=1\right.$, for instance $\mathrm{DS}_{1}$ or $\mathrm{DS}_{2}$ ) and

$D O C_{l k}^{\text {Real }}-D O C_{l k}^{\text {Predticted }}$ is the difference between the lth decision output concept (DOC) and its corresponding real value (target) when the kth set of input concept appears to the tool's input.

The performance evaluation was conducted and the results depicted in Table $\mathbf{3}$ shows that the proposed algorithm for FCMs performed effectively with $93.71 \%$ for HIV and 94.62 for TB performance accuracies respectively. considered, with Non-productive Cough $>3$ weeks $(\mathrm{C} 1=1.0)$, Severe Headache $(C 2=0.8)$, Severe Fever $(C 4=0.8)$, Moderate Weight Loss $(\mathrm{C} 5=0.5)$, Presence of Drenching Night Sweats $=(\mathrm{C} 6=1.0)$, Severe Sputum AFB $(\mathrm{C} 9=1.0)$, Severe Mautoux Test $(\mathrm{C} 10=0.7)$, Presence of Haemoptysis $(\mathrm{C} 11=1.0)$, Tachynea $(\mathrm{C} 12=0.7)$

Thus the initial state vector $V_{\text {Initial }}$ is:

$\begin{array}{lllllll}\text { C7 } & \text { C8 } & \text { C9 } & \text { C10 } & \text { C11 } & \text { C12 } & \text { DS }^{2} \\ 0 & 0 & 1.0 & 0.7 & 1.0 & 0.7 & 0]\end{array}$

at a fixed point with the final state vector (Decision Output Vector) $V_{\text {Final }}$ as:

$\begin{array}{cccccc}\text { C8 } & \text { C9 } & \text { C10 } & \text { C11 } & \text { C12 } & \text { DS }^{2} \\ 0 & 0.77 & 0.91 & 0.86 & 0.67 & 0.82]\end{array}$

Table 3: Performance Evaluation of Fuzzy Diagnostic algorithm

\begin{tabular}{|l|l|l|}
\hline & \multicolumn{2}{|c|}{$\begin{array}{c}\text { Fuzzy Diagnostic Predictive } \\
\text { Algorithm }\end{array}$} \\
\hline & HIV & TB \\
\hline $\begin{array}{l}\text { Mean Absolute } \\
\text { Error }\end{array}$ & 0.1343348 & 0.3881199 \\
\hline $\begin{array}{l}\text { Performance } \\
\text { Accuracy (\%) }\end{array}$ & 93.71 & 94.62 \\
\hline
\end{tabular}

On the basis of the performed experiments, it is possible to ascertain that the proposed algorithm really improves the prediction capabilities of FCMs. The prediction produced by FCM simulates the most likely future state of a patient. The knowledge on the predicted patient health status supports a physician in undertaking a timely medical intervention. To this end, the model offers great hope that the long battle to transform patient health status as passive to active services can be won since the output of the model can be considered as an indicator revealing to what extent the levels of healthcare supervision should be for each specific patient.

\section{CONCLUSION}

A new diagnostics predictive algorithm for FCMs was developed in this study for the management of HIV and TB.

The computational experiments proved the advantage of using the proposed methodology. Experimental results demonstrated that the new algorithm works better with respect to accuracy of FCMs.

Further research towards a systematic approach to develop FCM methods for dealing with missing values as well as evaluating the proposed scheme using more clinical cases taking into consideration the treatment plan model of the system can still be carried out. 


\section{REFERENCES}

[1] P.D.O. Davies, "The Role of DOTS in Tuberculosis Treatment and Control," America Journal of Respiratory and Critical Care Medicine, vol. 3, pp. 203-209, 2003.

[2] X.Y. Djam and Y.H. Kimbi, "A Decision Support System for Tuberculosis Diagnosis," Pacific Journal of Science and Technology, vol. 2, pp. 410-425, 2011.

[3] J. Greenhalgh, R. Flynn, A.F. Long, and S. Tyson, "Tacit and Encoded Knowledge in the Use of Standardized Outcome Measures in Multidisciplinary Team Decision Making: A Case Study of In-patient Neurorehabilitation. Social Science \& Medicine, 67(1):183-194, 2008.

[4] A.D. Harries and C. Dye, "Tuberculosis (Centennial Review). Annals of Tropical Medicine and Parasitology, vol. 100, pp. 415-431, 2006.

[5] B. Kosko, "Fuzzy Cognitive Maps," International Journal of Man-Machine Studies, vol. 24, pp. 65-75, 1986.

[6] E.I. Papageorgiou, C.D. Stylios, and P.P. Groumpos, "An integrated two-Level Hierarchical Decision Making System Based on Fuzzy Cognitive Maps (Fcms)," IEEE Transactions on Biomedical Engineering, vol. 50, pp. 1326-1339, 2003.

[7] E.I. Papageorgiou, P. Spyridonos, P. Ravazoula, P.P. Groumpos, and G. Nikiforidis, "A soft computing method for tumour grading cognitive maps, Journal of Artificial Intelligence in Medicine, vol. 36, 58-70, 2006.

[8] E.I. Papageorgiou, C.D. Stylios, and P.P. Groumpos, "Novel Architecture for Supporting Medical Decision Making of Different Data Types Based on Fuzzy Cognitive Map Framework," In Proc. o f $29^{\text {th }}$ IEEE EMBS Annual International Conference in Medicine and Biology Society, Lyon, France, 21-23, 2007.

[9] E.I. Papageorgiou, P. Spyridonos, D. Glotsos, C.D. Stylios, P. Ravazoula, G. Nikiforidis, and P.P.
Groumpos,"Brain Tumour Characterization Using Soft Computing of Fuzzy Cognitive Maps." Applied Soft Computing, vol. 8. PP. 820-828, 2008

[10] C.D. Stylios, V.C. Georgopoulos and P.P. Groumpos, "The Use of Fuzzy Cognitive Maps in Modeling Systems," Studies in Fuzziness and Soft Computing, vol. 5, pp. 18-30, 2011.

[11] C.D. Stylios and V.C. Georgopoulos, "Medical Decision Support Systems based on Soft Computing techniques," Preprints of the 18th IFAC World Congress Milano (Italy), pp. 14115-14120. August 2011.

[12] World Health Organization (2006). The Stop TB Strategy Document, WHO/HTM/TB, Geneva:WHO.

[13] L.A. Zadeh, "Fuzzy sets. Info. Control," vol. 3, pp. 338 353,1965 a

[14] L.A. Zadeh, "Fuzzy sets and Systems. In Proc. of International Symposium on System Theory," Polytechnic Institute of Brooklyn, pp. 234-241, $1965 \mathrm{~b}$.

[15] L.A. Zadeh, Biological applications of the theory of fuzzy set and systems, In Proc. of International Symposium on Biocybernetics of the Central Nervous System (Little, Brown and Company, Boston), pp. 199206, 1969.

[16] M. Musen, Y. Shahar, and E. Shortliffe, E. "Clinical decision support systems," In: E. Shortliffe, L. Perreault, eds. Medical Informatics: Computer Applications in Health Care and Biomedicine. New York, NY: SpringerVerlag New York, Inc; 573-609, 2001.

[17] J. W. Grzymala-Busse and M. Hu, "A comparison of several approaches to missing attribute values in data mining," Rough Sets Current Trends Comput, pp. 378$385,2000$.

\section{Appendix}

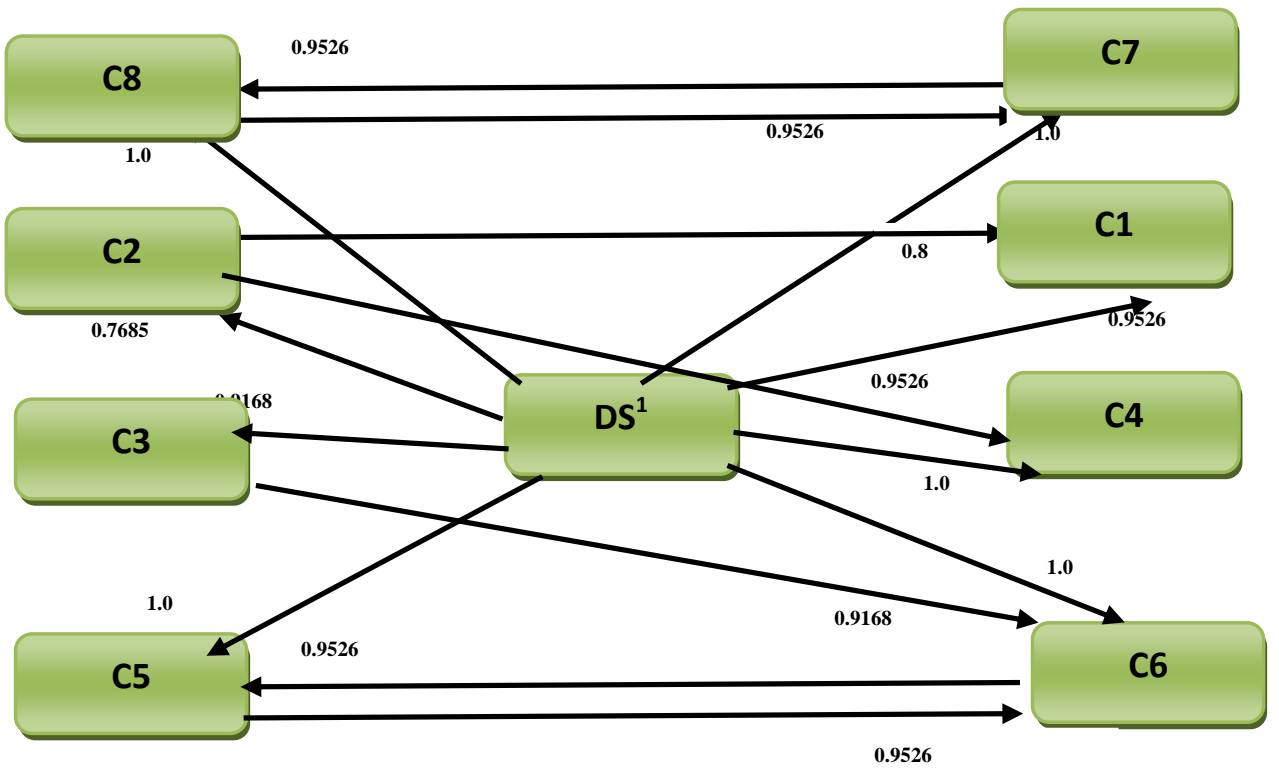

Figure1: Augmented FCM Model for Assessing the Severity of HIV 
Table 4: Overall weight matrix for HIV

\begin{tabular}{|l|l|l|l|l|l|l|l|l|l|}
\hline & C1 & C2 & C3 & C4 & C5 & C6 & C7 & C8 & DS $^{1}$ \\
\hline C1 & 0 & 0 & 0 & 0 & 0 & 0 & 0 & 0 & 0 \\
\hline C2 & 0.8 & 0 & 0 & 0.9526 & 0 & 0 & 0 & 0 & 0 \\
\hline C3 & 0 & 0 & 0 & 0 & 0 & 0.9168 & 0 & 0 & 0 \\
\hline C4 & 0 & 0 & 0 & 0 & 0 & 0 & 0 & 0 & 0 \\
\hline C5 & 0 & 0 & 0 & 0 & 0 & 0.9526 & 0 & 0 & 0 \\
\hline C6 & 0 & 0 & 0 & 0 & 0 & 0 & 0 & 0 & 0 \\
\hline C7 & 0 & 0 & 0 & 0 & 0 & 0 & 0 & 0.9526 & 0 \\
\hline C8 & 0 & 0 & 0 & 0 & 0 & 0 & 0.9526 & 0 & 0 \\
\hline DS & 0.9526 & 0.7685 & 0.9168 & 1.0 & 1.0 & 1.0 & 1.0 & 1.0 & 0 \\
\hline
\end{tabular}

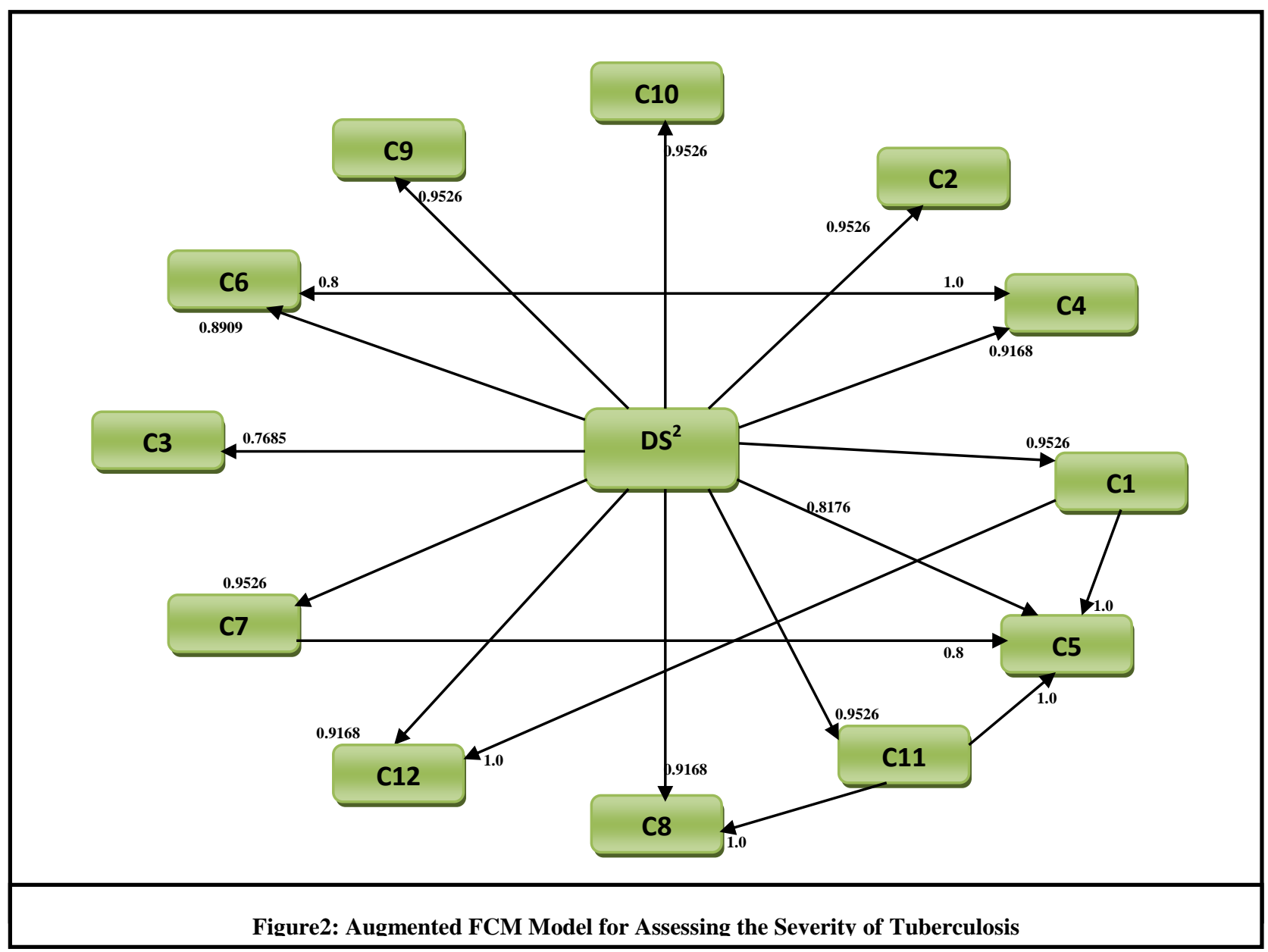

Table 5: Overall weight matrix for Tuberculosis

\begin{tabular}{|l|l|l|l|l|l|l|l|l|l|l|l|l|l|}
\hline Concepts & C1 & C2 & C3 & C4 & C5 & C6 & C7 & C8 & C9 & C10 & C11 & C12 $^{\text {DS }}$ \\
\hline C1 & 0 & 0 & 0 & 0 & 1.0 & 0 & 0 & 0 & 0 & 0 & 0 & 1.0 & 0 \\
\hline
\end{tabular}




\begin{tabular}{|c|c|c|c|c|c|c|c|c|c|c|c|c|c|}
\hline C2 & 0 & 0 & 0 & 0 & 0 & 0 & 0 & 0 & 0 & 0 & 0 & 0 & 0 \\
\hline $\mathrm{C3}$ & 0 & 0 & 0 & 0 & 0 & 0 & 0 & 0 & 0 & 0 & 0 & $\mathbf{0}$ & 0 \\
\hline $\mathrm{C} 4$ & 0 & 0 & 0 & 0 & 0 & 0.8 & 0 & 0 & 0 & 0 & 0 & 0 & 0 \\
\hline C5 & 0 & 0 & 0 & 0 & 0 & 0 & 0 & 0 & 0 & 0 & 0 & $\mathbf{0}$ & 0 \\
\hline C6 & 0 & 0 & 0 & 1.0 & 0 & 0 & 0 & 0 & 0 & 0 & 0 & 0 & 0 \\
\hline C7 & 0 & 0 & 0 & 0 & 0.8 & 0 & $\mathbf{0}$ & 0 & 0 & 0 & 0 & 0 & 0 \\
\hline C8 & 0 & 0 & 0 & 0 & 0 & 0 & 0 & 0 & 0 & 0 & 0 & 0 & 0 \\
\hline C9 & 0 & 0 & 0 & 0 & 0 & 0 & 0 & 0 & 0 & 0 & 0 & 0 & 0 \\
\hline C10 & o & 0 & 0 & $\mathbf{0}$ & o & 0 & 0 & 0 & 0 & 0 & 0 & o & 0 \\
\hline C11 & o & 0 & 0 & 0 & 1.0 & 0 & 0 & 1.0 & 0 & 0 & 0 & & 0 \\
\hline $\mathrm{C} 12$ & 0 & 0 & 0 & 0 & 0 & 0 & 0 & 0 & 0 & 0 & 0 & 0 & 0 \\
\hline $\mathrm{DS}^{2}$ & 0.9526 & 0.9526 & 0.7685 & 0.9168 & 0.8176 & 0.8909 & 0.9526 & 0.9168 & 0.9526 & 0.9526 & 0.9526 & 0.9168 & 0 \\
\hline
\end{tabular}

